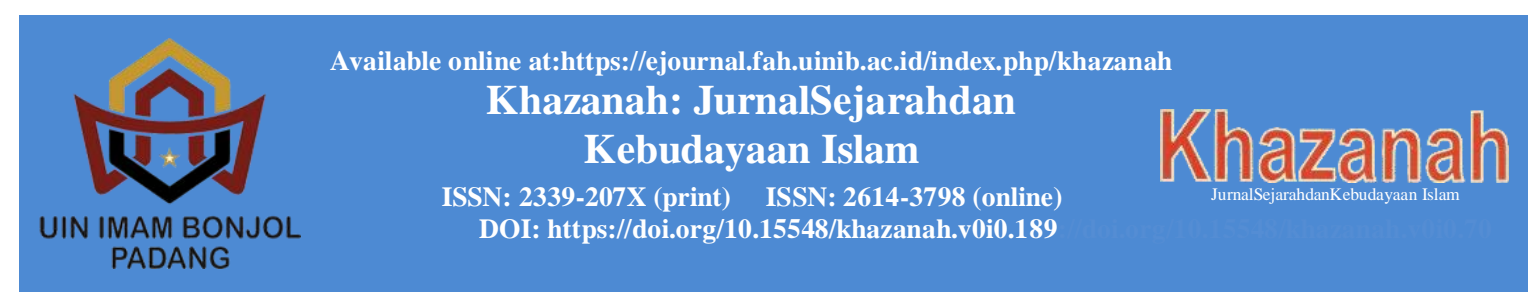

\title{
NILAI-NILAI YANG TERKADUNG DALAM TRADISI MAKAN BAJAMBA DI KECAMATAN TILANTANG KAMANG
}

\author{
Yulniza \\ email: yulnizanurbit@gmail.com \\ Fakultas Adab dan Humaniora UIN Imam Bonjol Padang
}

\begin{abstract}
Eating Bajamba is a tradition that is still maintained by the people of the Tilatang Kamang sub-district until now. Eating bajamba for the people of Tilatang Kamang is not just eating together, but has certain values that are very valuable and educate members of the community to respect and appreciate each other. The purpose of this study is to describe the values contained in the tradition of eating bajamba. In Tilatang

Kamang sub-district, Agam district, West Sumatra. This study uses ethnographic research methods and data collection is done through observation, interviews and documentation. From the results of the study it was found that eating bajamba in the Tilatang Kamang district contains the value of togetherness, ethical values and the value of friendship. The many values contained in this bajamba meal then this tradition is maintained by the people of Tilatang Kamang, especially in weddings.
\end{abstract}

Keywords: Bajamba Eating Values

\begin{abstract}
Abstrak
Makan bajamba merupakan tradisi yang masih dipertahankan oleh masyarakat kecamatan Tilatang Kamang sampai sekarang. Makan bajamba bagi masyarakat Tilatang Kamang bukan hanya sekedar makan secara bersama-sama saja akan tetapi mepunyai nilai-nilai tertentu yang sangat berharga dan memdidik anggota masyarakatnya untuk saling menghormati dan menghargai. Tujuan dari penelitian ini adalah mengambarkannilai-nilai yang terkandungdalamtradisimakanbajamba di

kecamatan Tilatang Kamang Kabupaten Agam Sumatera Barat. Penelitian ini menggunakan metode penelitian etnografi dan pengumpulan datanya dilakukan melalui observasi, wawancara dan dokumentasi. Dari hasil penelitian ditemukan bahwa makan

bajamba di Kecamatan Tilatang Kamang ini mengandung nilai kebersamaan, nilaietikadannilaisilaturahmi. Banyaknyanilai yang terkandung dalam makan bajamba ini maka tradisi ini tetap dipertahankan oleh masyarakat Tilatang Kamang khususnya dalam pesta perkawinan
\end{abstract}

Kata Kunci: Nilai-Nilai Makan Bajamba 


\section{PENDAHULUAN}

Indonesia merupakan negara yang akan akan budaya dan tradisi. Hampir setiap daerah di Indonesia memiliki budaya dan tradisinya masing-masing yang tersebar dari Sabang sampai Merauke. Diantara budaya-budaya tersebut ada yang masih tetap dipertahankan dan diwariskan kepada generasi berikutnya agar tidak hilang. Keaneka ragaman budaya dan tradisi inilah yang membuat yang membuat negara Indonesia kaya akan budaya dan tradisi.Salah satu suku di Indonesia yang masih kental tradisinya adalah Minangkabau. Masyarakatnya Minangkabau ini juga dikenal sebagai masyarakat yang kaya akan kebudayaannya. Suku Minangkabau memiliki adat istiadat yang kuat dalam mengatur tata kehidupan masyarakatnya. Fernandes juga menambahkan bahwa selain dalam bidang kesenian karawitannya, masyarakat Minangkabau juga terkenal dengan seni tuturnya.(Fernandes, 2016).

Budaya dan tradisi yang berkembang di Minangkabau berbeda antara satu daerah dengan daerah seperti yang terungkap dalam ungkapan Minang adat salingka nagari, jadi masing-masing nagari di Minangkabau ini punya tradisi asing-masing yang terus mereka wariskan kepada generasi berikutnya. Salah satu tradisi suku Minangkabau yang masih dilaksanakan dalam setiap acara perkawinan yaitu makan bajamba atau makan barapak.Tradisi ini merupakan suatu tradisi masyarakat Minangkabau yang dilaksanakan pada acara-acara adat salah satunya acara perkawinan.Makan bajamba adalah sebuah tradisi masyarakat makan dalam satu piring besar yang beranggotaan lima sampai tujuh orang yang didalamnya sudah terdapat berbagai macam lauk pauk yang dihidangkan oleh tuan rumah pada saat acara dilakukan. Makan bajamba berasal dari kata makan dan jamba. Jamba sendiri memiliki arti hidangan yang disajikan pada sebuah pinggan (piring) besar. Dapat diartikan bahwa makan bajamba merupakan makan dengan menggunakan pinggan besar secara bersama-sama dalam sebuah ruangan yang sudah ditentukan. Adapun tujuan dari dilaksanakannya makan bajamba ini ialah untuk memupuk tali silaturahmi antar masyarakat Minangkabau

Tradisi makan bajamba sudah ada sejak zaman dahulu dan merupakan tradisi bermakna bagi Masyarakat Minangkabau.Tradisi ini masih dijalankan oleh masyarakat Minangkau di daerah Tilatang Kamang. Anggota makan bajamba di daerah ini ditentukan sebuah pinggan besar tersebut biasanya diisi oleh tiga sampai lima orang yang duduk melingkar. Jumlahnya tergantung kepada besarnya pinggan yang digunakan, jika pinggan agak kecil maka jumlahnya tiga sampai lima orang, tetapi jika pinggan yang digunakan besar maka jumlah anggota yang makan tersebut lima sampai tujuh orang. Nilai-nilai yang terkandung dalam pelaksanaan makan bajamba pada acara perkawinan di Tilatang Kamang banyak sekali salah satunya menumbuhkan rasa kebersamaan, tolerasi, saling menghargai dan disiplin diri dan memupuk silaturahmi.

Tradisi adat ini di Sumatera Barat sudah mulai memudar, karena tidak semua daerah yang ada di Sumatera barat melaksanakan tradisi makan bajamba pada hari-hari besar adat seperti acara perkawinan, acara turun mandi, khatam qur'an, pengangkatan penghulu dan kematian.Kecamatan Tilatang Kamang merupakan salah satu kecamatan yang terletak di Kabupaten Agam Sumatera Barat. Kecamatan ini merupakan kecamatan yang tinggi tingkat kepadatan penduduknya, yaitu sekitar 615,5 jiwa/km. Daerah ini merupakan daerah yang masih kental dengan tradisinya, salah satunya adalah tradisi makan bajamba dalam pesta perkawinan. Hal ini disebabkan karena tradisi tersebut banyak mengandung 
nilai yang sangat berguna dalam kehidupan masyarakat.Oleh sebab itu masih tetap mempertahankan tradisi makan bajamba dalam acara pesta perkawinan, karena tradisi ini mencerminkan jiwa kebersamaan dalam masyarakat.

\section{METODE PENELITIAN}

\begin{tabular}{llll}
\multicolumn{1}{c}{ Jenis } & penelitian ini & adalah \\
penelitian & lapangan & & dengan \\
menggunakan & & & metode
\end{tabular}
etnografi.Etnografi dapat didefinisikan sebagai usaha untuk mendiskripsikan kebudayaan secara mendalam.(Ihromi, 1999). Oleh sebab itu dapat dikatakan kalau Metode etnografi ini merupakan metode penelitian yang dapat mengambarkan kebudayaan secara mendalam dengan tujuan nya adalah untuk memahami suatu pandangan hidup dari sudut pandang penduduknya. Hal ini sesuai dengan apa yang diungkapkan oleh Malinowski (Spradly, 1997) bahwa tujua utama dari metode etnografi ini adalah untuk memahami sudut pandang penduduk setempat, Oleh sebab itu metode etnografi ini dirasa sangat cocok dipakai untuk mengambarkan nilai-nilai yang terdapat dalam tradisi makan bajamba diKecamatan Tilatang Kamang ini. Teknik Pengumpulan data dilakukan melaui observasi.Metode observasi adalah metode pengumpulan data yang digunakan untuk menghimpun data penelitian melalui pengamatan dan penginderaan (Bungin, 2008) dilakukan melaui observasi. Metode Observasi adalah metode pengumpulan data penelitian. Wawancara, wawancara adalah dialog dengan tujuan tertentu yang dilakukan oleh dua pihak yaitu pihak pewancara dan pihak yang diwawancarai.(Maleong, 2000). Dokumentasi,dokumentasi adalah teknik pengumpulan data dengan cara mendapatkan informasi dari berbagai sumber tertulis atau dokumen yang terdapat pada responden atau tempat, dimana responden bertempat tinggal atau melakukan aktivitas sehari-hari. (Sugiyono, 2010) DoKumentasi ini dapat berbentuk gambar, tulisan ataupun karya-karya lainnya.Penelitian ini di lakukan di Kecamatan Tilatang Kamang Kabupaten Agam.

\section{PEMBAHASAN}

\section{Nilai Kebersamaan}

Sebagai masyarakat Indonesia, kita harus mengetahui berbagai macam kebudayaan yang ada di negara kita.Setiap suku bangsa yang ada di Indonesia hidup dengan membentuk, menjalankan dan mengembangkan adat, tradisi serta kebiasaan-kebiasaan yang sesuai dengan kebutuhan mereka.Adat dan tradisi ini merupakan bagian dari budaya yang mereka ciptakan dan memiliki ciri khas tersendiri bagi suku bangsa tersebut.ciri khas yang mereka bentuk itulah membedakan suku bangsa tersebut dengan sukusuku lainnya yang ada di Indonesia. Keragaman suku, etnis, agama, dan ras yang ada di Indonesia, maka lahirlah adat dan kebudayaan yang berbeda pula disetiap daerah sehingga masyarakat Indonesia dikenal dengan negara yang bermasyarakat majemuk atau multicultural(Hafizh, 2019)

Nilai juga dikatakan sebagai suatu prinsip kelakuan yang abstrak yang digeneralisasikan dengan memuatkan perasaan emosi yang kuat dalam peneliti zaman yang positif lalu memberikan suatu piawai untuk menetapkan sesuatu tindakan (Theodorson \& Theodorson, 1979 dalam Amat Juhari, 2001 :284). Sistem nilai memberikan rangka kerja untuk penganalisisan norma-norma masyarakat, keunggulan, kepercayaan, dan kelakuan. Nilai menjadi ukuran dan pegangan tentang baik buruk sesuatu perlakuan berdasarkan kelaziman atau kebiasaan dalam suatu 
masyarakat (Wan Abdul Kadir, 2000:4) (Rashid et al., 2005).

Makan bajamba bagi masyarakat Kecamatan Tiltang Kamang bukan hanya sekedar makan secara bersama-sama saja, akan tetapi memiliki nilai-nilai yang sangat berharga.(Ernalis, wawancara: 2021)Nilai-nilai yang terkandung dalam makan bajamba yang dilakukan oleh masyarakat Tilatang Kamang ini di antaranya adalah nilai kebersamaan.Maksud dari nilai kebersamaan di sini adalah memupuk rasa kekeluargaan di antara masyarakat sekitar tanpa adanya perbedaan.Nilai kebersamaan ini tidak bisa tumbuh secara instan atau secara cepat tetapi harus melalui pembiasaan. Salah satu cara untuk memupuk rasa kebersamaan ini pada masyarakat Tilatang Kamang adalah melalui makan bajamba.

$$
\text { Makan bajamba bagi }
$$

masyarakat Tilatang Kamang ini menggambarkan duduk sama rendah tegak sama tinggi, tidak memandang kaya atau miskin, tua ataupun muda, semuanya sama, makan dalam satu piring besar (Dt. Basa Batuah, wawancara: 2021). Dalam makan bajamba tersebut semua orang dalam satu pinggantersebut duduk melingkari pinggan dan makan secara bersama-sama. Namun dalam makan bajamba ini ada hal-hal yag harus diperhatikan seperti tidak boleh makan duluan juga tidak boleh siap duluan. Kalau seseorang sudah kenyang dan selesai makan sementara orang lain dalam pinggan tersebut masih ada yang belum siap maka orang yang sudah kenyang tersebut tidak boleh mencuci tangan terlebih dahulu, harus menunggu semua orang yang dalam satu pinggan itu selesai makan. Begitu juga selesai makan tidak boleh berdiri dan keluar duluan sebelum orang yang dekat pintu selesai makan(Elma, wawancara: 2021).
Biasanya dalam satu pinggan tersebut terdiri dari tiga sampai lima atau lima sampai tujuh orang tergantung pada besar kecilnya pinggan yang dihidangkan.(Elidawati, wawancara: 2021)

Nilai kebersamaan dalam makan bajamba ini membawa kehidupan masyarakat dapat berjalan dengan aman, damai dan tenteram. Hal ini disebabkan karena tidak adanya perbedaan status sosial di tengah-tengah masyarakat. Semua masyarakat hidup saling hormat menghormati dan saling menghargai antara satu sama lain. Nilai kebersamaan inilah yang harus diturunkan kepada generasi muda agar mereka nantinya dalam masyarakat senantiasa saling menghormati dan saling menghargai.

\section{Nilai Etika}

Secara etimologi kata etika berasal dari bahasa Yunani yaitu ethos dan ethikos Ethos berarti sifat, watak, adat dan kebiasaan.Sedangkan ethikos berarti susila, keadaban atau kelakuan dan perbuatan yang baik. (Sukron Kamil: 2021). Etika memiliki sudut pandang yang normatif dimana objeknya adalah manusia.Di samping itu etika juga mencakup penerapan konsep seperti benar, salah, baik dan buruk.Secara umum dapat dikatakan bahwa pada dasarnyaa etika adalah suatu peraturan yang bisa digunakan sebagai acuan bagi prilaku seseorang sebagai makhluk sosial dalam berinteraksi di tengah-tengah masyarakat.

Berdasarkan hasil pengamatan di lapangan dan wawancaa dengan tokoh adat, bundo kanduang dan masyarakat yang ada di Kecamatan Tilatang Kamang ini terlihat bahwa makan bajamba ini mengandung nilai etika yang harus diperhatikan dan dilaksanakan oleh masyarakatnya. Diantara nilai etika tersebut adalah: 
Satu. Tidak boleh mengambil makanan yang jauh dari posisi duduk pada saat makan dan diharuskan untuk mengambil makanan yang dekat sekalipun makanan tersebut kurang sesui dengan selera. Kalau mangambil makanan yang jauh dari posisi tempat duduk bisa dibilang orang tersebut tidak beretika.Kedua, tidak boleh makan duluan sebelum dipersilahkan oleh tuan rumah. Biasanya dalam setiap makan bajamba tersebut masing-masing jamba itu ditemani salah seorang keluarga dari orang yang melaksanakan pesta. Orang ini lah yang nantinya akan memasukkan aneka ragam sambal ke dalam pinggan dan yang akan mempersilahkan tamunya makan. Ketiga, makanan harus habis. Semua makanan yang sudah dimasukkan oleh tuan rumah tersebut harus dihabiskan (tidak boleh bersisa) karena kalau bersisa akan menjadi mubazir, sementara mubazir tersebut dilarang oleh agama. Kalau seandainya makanan tersebut masih ada sisa di dalam pinggan maka akan dibagi secara bersama agar makanan tersebut habis. Keempat, makan tidak boleh berbunyi yang dalam bahasa Tilatang Kamangnya disebut dengan istilah "Mancapak". Makan dengan cara mancapak tersebut membuat orang sekitar merasa tidak nyaman dan bahkan akan membuat hilangnya selera makan orang.Untuk itu makan dalam makan bajamba ini harus pelan. Kelima,tidak boleh memasukkan jari ke dalam mulut. Pada saat memasukkan nasi kedalam mulut jari tidak boleh masuk artinya makanan diambil dari pinggan dengan cara melempar ke dalam mulut yang dilakukan oleh tangan kanan dan ditopang oleh tangan kiri. Keenam, tidak boleh mencuci tangan terlebih dahulu sekalipun sudah selesai makan sebelum semua anggota yang dalam pinggan tersebut selesai makan. Orang yang mencuci tangan terlebih dahulu adalah yang tua.(Dt. Maruhum Basa, Asnida dan Ernalis, Wawancara:
2021). Di samping itu,tanpa disadari makan bajamba ini telah membuat orang melakukan pengawasan terhadap diri sendiri dan saling mengawasi satu sama lain agar tidak berprilaku makan yang rakus, karena dalam makan bajamba tersebut nasi dan aneka ragam lauk pauk yang sudah dimasukkan ke dalam pinggan itu harus dihabiskan secara bersama dan terkhir kalau masih ada bersisa dibagi secara adil agar tidak mubazir dan dapat juga dikatakan kalau makan bajamba ini merupakan salah satu cerminan sifat anti korupsi.

\section{Nilai Silaturrahmi}

Tradisi yang ada pada masyarakat ini memiliki tujuan supaya kehidupan mereka kaya akan budaya dan nilainilai yang sangat berharga dari budaya dan tradisi tersebut. Di samping itu, tradisi ini juga akan membuat kehidupan masyarakat menjadi harmonis. Tetapi hal ini akan terwujud jika manusia menghargai, menghormati, dan menjalankan suatu tradisi dengan baik dan benar dan juga sesuai dengan aturan. Kebudayaan dapat dianggap sebagai peraturanperaturan yang berlaku di dalam masyarakat. Peraturan dipelajari dan tidak diperoleh dari warisan biologis, karena peraturan merupakan petunjuk untuk perilaku sehari-hari dalam kelompok masyarakat.Perilaku manusia yang dilakukan terus menerus dan dilakukan oleh manusia disebut perilaku kebudayaan. Tujuan tindakan kebudayaan adalah segala tindakan yang harus dibiasakan oleh manusia dengan belajar (Hafizh, 2019). Salah satu nilai dari tradisi tersebut adalah ajang silaturrahmi

Secara etimologi silaturrahmi merupakan gabungan dari dua kata yaitu Shilah dan ar-Rahmi.Kata shilah berarti hubungan atau yang menghubungkan sedangkan arRahim/ar-Rahmi berarti kerabat yang masih ada pertalian darah .Di samping itu ar-Rahim juga berarti 
lembut, penuh cinta, dan kasih sayang.Secara Terminologi kata silaturrahmi berarti menghubungkan tali kekerabatan atau menghubungkan tali kasih sayang.(H. Amirulloh Syarbini, 2017). Menjalin tali silaturahmi atau menjalin tali kasih sayang ini sangat dianjurkan dalam agama karena ini akan membawa kebahagiaan hidup di dunia dan akhirat.

Tradisi makan bajamba diKecamatan Tilatang Kamang ini, di samping mengandung nilai kebersamaan dan nilai etika juga mengandung nilai silaturrahmi. (Dt. Maruhum Basa, wawancara: 2021). Terjalinnya hubungan silaturrahmi diantara masyarakat ini tergambar pada saat mereka menyantap makanan dengan nasi yang sama dan sambal yang sama, yang disediakan oleh tuan rumah. Mereka sama-sama merasakan masakan dari tuan rumah tanpa memandang status sosial mereka di masyarakat. Kaya miskin, tua muda makan dalam satu wadah/pinggan yang sama, mereka menyantap makanan yang sudah dimasukkan ke dalam pinggan sampai habis. Selesai makan sebelum berdiri dan pulang mereka saling bercengkrama bersama.Oleh sebab itu dapat dikatakan kalau makan bajamba ini dapat dikatakan sebagai ajang untuk membangun tali siaturrahmi di antara masyarakat seperti yang jarang bertemu, jarang bercengkrama disinilah tempatnya mereka membina hubungan kekeluargaan di antara mereka. Untuk itu menurut salah seorang orang yang dituakan di sini tradisi makan bajamba harus dipertahankan (Asnida, wawancara: 2021)

\section{KESIMPULAN}

Makan bajamba di Kecamatan Tilatang Kamang Kabupaten Agam Sumatera Barat merupakan satu tradisi yang dilakukan oleh masyarakat pada acara-acara tertentu salah satunya adalah acara perkawinan. Makan bajamba pada tradisi masyarakat Tilatang Kamang ini mengandung nilai-nilai seperti, nilai kebersamaan. Nilai kebersamaan disini tergambar makan bersama dalam satu piring besar (pinggan) yang terdiri dari tiga sampai lima atau lima sampai tujuh orang, nilai etika. Nilai etika ini terlihat karena pada saat makan ada aturan tidak tertulis yang harus dipenuhi oleh anggota yang ikut makan, artinya tidak boleh mengambil makanan selain makanan yang ada di depan, dan ketika duluan selesai makan tidak boleh mencuci tangan terlebih dahulu harus menunggu semua anggota selesai makan dan nilai silaturahmai. Nilai silaturrahmi di sini tergambar dari keakraban yang dipelihara oleh para anggota yang makan dalam dalam satu pinggan itu tanpa memandang status sosial semuanya sama, makan bersama, ketawa bersama dan menikmati makan secara bersama-sama. 


\section{DAFTAR KEPUSTAKAAN}

Ade, S. (2018). Makna Simbolik Prosesi Makan Bajamba Dalam Baralek Adat Minangkabau Di Desa Baso Kabupaten Agam Provinsi Sumatera Barat Oleh: Jom Fisip, 5(1), 1-13.

Fernandes, R. (2016). Tradisi Pasambahan Pada Masyarakat Minangkabau (Studi Tentang Pelaksanaan Tradisi Pasambahan Manjapuik Marapulai Di Dusun Tampuak Cubadak, Jorong Koto Gadang, Nagari Koto Tinggi, Kecamatan Baso, Kabupaten Agam, Sumatera Barat) Oleh: Jom Fisip, 3(2), 1-9.

Gustina, M. (2019). Tradisi Makan Bajamba Dalam Alek Perkawinan Di Nagari Magek Provinsi Sumatera Barat Oleh. JOM Fisip, 6 , 1-13. https://ejournal.undiksha.ac.id/inde x.php/JJPBS

Hafizh, A. (2019). Tradisi makan bajambau di desa salo timur kecamatan salo kabupaten kampar. Peran dalihan na tolu dalam pelaksanaan upacara perkawinan masyarakat batak toba Di Kelurahan Tanjung Penyembal Kota Dumai Oleh, 6, 1-13. https://ejournal.undiksha.ac.id/inde x.php/JJPBS

Rashid, N. A., Dalam, N., \& Melayu, B. M. (2005). Nilai Kesantunan Dalam Konteks Sosiobudaya Masyarakat Melayu.

Maleong, Lexy J. 2006. Metodologi Penelitian Kualitatif. Bandung: PT Remaja Rosdakarya Offset

Sugiyono. 2017. Metode Penelitian Kualitatif. Bandung: Alfabeta

Wawancara:

Volume 11, Nomor 1, Januari-Juni 2021
1. Asnida. Wawancara, 10 April 2021

2. A. Dt. Maruhum Basa,Wawancara, 10 April 2021

3. Elma, wawancara, 10 April 2021

4. Elidawati, wawancara, 15 Mei 2021

5. Ernalis. Wawancara, 15 Mei 2021

6. Dt, Basa Batuah, wawancara $15 \mathrm{Mei}$ 2021

7. Suharti, wawancara, 22 Mei 2021 